\title{
Ion Lasers-The Early Years
}

\author{
William B. Bridges, Life Fellow, IEEE
}

\author{
Invited Paper
}

\begin{abstract}
This paper is a personal, anecdotal history of the discovery and early development of ion lasers, particularly the argon ion laser. A brief discussion of the mechanisms that make this laser work, and the engineering challenges and developments that make it practical are included. Some early applications in night reconnaissance and imaging are included.
\end{abstract}

\section{WHAT THIS PAPER IS ABOUT}

W HEN I was invited to write a paper on the early days of ion lasers for this special issue, I hesitated. So much was done by so many people so long ago, that it seemed impossible to put it all into a single paper with any kind of balance. In the end, I decided to write about the early days from a personal perspective, rather than try to include all developments in all the organizations. If I can convey the rampant excitement of those early years that surrounded the ion laser, both its development as a device and its prospects for application, then I will have succeeded, even if the perspective is that of a researcher in a large aerospace company, driven by military applications. Someone else will have to write the story of the rise and fall of the commercial laser manufacturers and applications that eventually came to dominate the marketplace (and all the interesting lawsuits over intellectual property that ensued).

Perhaps this perspective is not too bad for the very early days of ion lasers, since most of the players were researchers in large systems organizations: Hughes, Bell Telephone Laboratories, Raytheon, RCA. Only Spectra Physics, then a relatively small company, newly formed by people from Varian Associates but growing rapidly as a successful manufacturer of helium-neon lasers, was "commercial." Bankrolling the research and development was the Department of Defense. (Even Spectra Physics had contracts from the Air Force). This was psychologically a different era. It never crossed my mind to leave Hughes and seek venture capital to start up a small ion laser manufacturing company, something that would happen in an instant if it were discovered today! So perhaps this paper can serve as a window on those earlier times, as well as a partial record of the technical history.

I have included the mistakes and side alleys, as well as successes and the mainstream. I believe it is important for engineers to know that progress is not made in a simple straight line of successes (although that is always what we write in proposals

Manuscript received September 26, 2000.

The author is with the California Institute of Technology, Pasadena, CA 91125 USA.

Publisher Item Identifier S 1077-260X(00)11498-4. for new work!) I have chosen to include people and their firsthand interactions in this account. History is made by people, not organizations or projects or programs. The risk of including individuals in any narrative is that you will leave someone out. I admit up front that I have "left out" literally hundreds of people, even from these earliest days (check the bibliographies of any of the summary articles listed in the References). To these, I can only say "I'm sorry... But those were really great times, weren't they?"

\section{IN THE BEGINNING WAS MERCURY}

Strictly speaking, the first ion laser was Maiman's ruby laser in 1960, since the energy levels involved are those of triply ionized chromium, $\mathrm{Cr}^{3+}$, albeit in an aluminum-oxide crystal host. But this paper is about ions that lase in a gaseous or vapor form, and the first of these was singly ionized mercury, $\mathrm{Hg}^{+}$, demonstrated in late 1963 by W. Earl Bell of Spectra Physics [1]. He obtained oscillation at $615 \mathrm{~nm}$ in the red-orange, and $568 \mathrm{~nm}$ in the green, as well as two infrared lines at 735 and $1058 \mathrm{~nm}$, in a pulsed helium-mercury discharge. These four wavelengths were known to originate from energy levels in singly ionized mercury, making them members of the "second spectrum" of mercury, $\mathrm{Hg}$ II. The reported output power was of the order of tens of Watts for microseconds, and the repetition rate was high enough to make the laser output quite visible by scattering from dust in the air. Fig. 1 appeared (in color) in a Spectra Physics advertisement in 1964, and shows Bell posed next to a laboratory mercury ion laser with a striking green laser beam exiting. (This figure is one of many in my "A Boy and His Laser" photograph collection.)

Since this was the first green laser, it created a bit of excitement, at least in the organization I then worked for, the Hughes Research Laboratories (HRL) of the Hughes Aircraft Company, and I decided to make one in my laboratory. My scientific "excuse" was that Bell had not speculated in his paper on the mechanisms involved that lead to the oscillation. I had been studying mechanisms, particularly those in mixtures of gases, so it was a natural extension to look at this new laser. Recall that the well-known red helium-neon laser uses resonant collisional exchange between the helium singlet metastable levels and neon atoms to preferentially excite the neon upper level. However, many other neutral noble gas transitions were known to oscillate in mixtures with helium without any particular resonant process involved. In 1963, I was looking at mechanisms in the strong $3.5-\mu \mathrm{m}$ neutral line in xenon, and concluded that helium was helpful but not necessary for oscillation or 


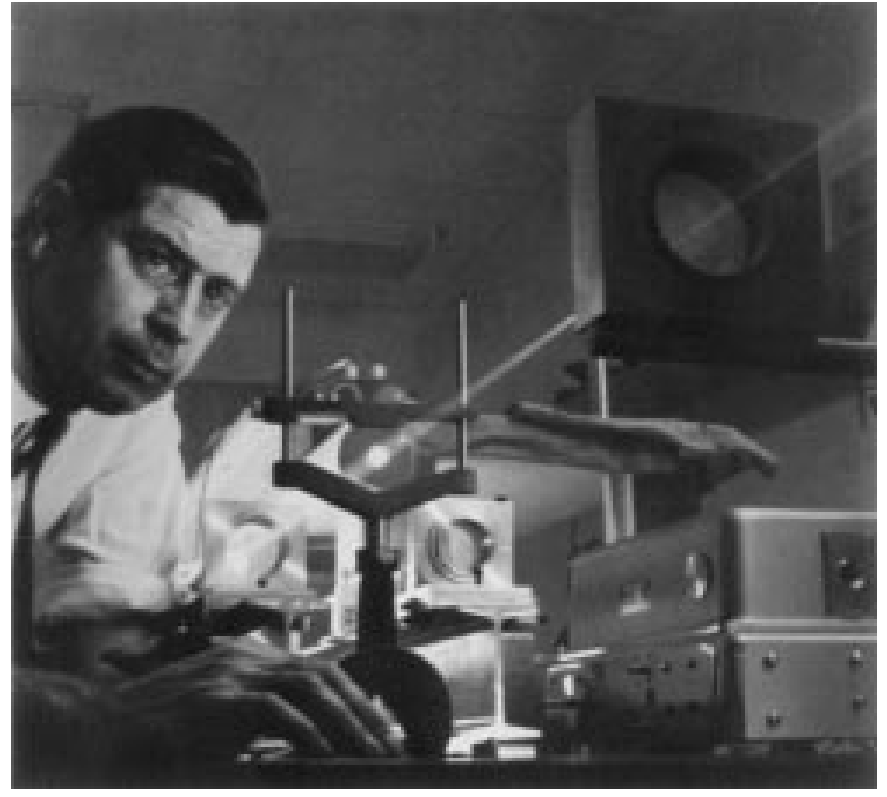

Fig. 1. W. Earl Bell and his green mercury ion laser (from a color brochure from Spectra Physics, circa 1965).

high optical gain [2]. Thus it was natural to try to figure out what role, if any, the helium played in the helium-mercury ion laser.

I had the HRL glass shop build a discharge tube similar to Bell's, and on February 7, 1964, I duplicated Bell's pulsed oscillation on 615 and $568 \mathrm{~nm}$ with a small amount of mercury in a helium discharge. The mercury pressure was controlled by immersing a glass side-arm in a dewar of liquid nitrogen. I used a high-voltage high-current pulse generator, left over from earlier microwave vacuum tube research at Hughes. This pulser could generate square voltage pulses up to eight microseconds in length, without the decaying current "tails" typical of a simple capacitor discharge. The first thing I noted was that the green and red lines began to oscillate several microseconds after the discharge current ended, that is, in the discharge "afterglow," and the green and red lines did not oscillate simultaneously in time. This suggested that some kind of transfer of excitation from atom to atom was involved in the excitation process, rather than electron collision. The "afterglow" nature of the output suggested that high-power $\mathrm{CW}$ operation was not likely, since the absence of electrons seemed to be required. Actually, my thinking along these lines was by analogy with the helium-neon system, in which continuous low-power operation can be obtained, but much higher powers can be obtained in the afterglow of pulsed discharges (see, e.g., [3, Sec. 2.3.1.4]).

Early the next week, I swung by Bell Telephone Laboratories (BTL) on the way to business visits at NASA Goddard and Wright-Patterson AFB. I visited Eugene I. Gordon at Bell, and discussed my $\mathrm{Hg}$ laser results with him, noting that the afterglow output suggested that this would not make a good candidate for a CW laser. He agreed. I told Gene that I was planning on trying neon instead of helium, to see if there was a resonance in the transfer of excitation. He told me that J. Dane Rigden, a former BTL colleague now at Perkin-Elmer Corporation had also built a pulsed $\mathrm{He}-\mathrm{Hg}^{+}$laser and had substituted neon for the helium, with the result that the mercury ion lines continued to oscillate. It seemed clear that there was nothing "resonant" about helium collisions. He suggested that I try argon as well as neon as a further test of this "nonresonance."

When I got back to HRL at the end of that week, I tried Rigden's experiment myself. The resulting neon-mercury discharge also produced the 568-nm line (but not the 615-nm line), thus demonstrating that resonant collisions with helium were not involved, at least for the green line. The appearance of this laser was quite striking, since the green laser output now exited a bright pink discharge. As the "clincher" experiment mentioned above, I tried using argon instead of helium as the buffer gas. While I had bottles of spectroscopic-grade helium, neon, and xenon already on my laser process station from previous experiments, I did not have argon. It would have taken a week or so to have the glass blower attach a flask of spectroscopic-grade argon, so I asked my technical assistant, Robert B. Hodge, to see if he could scare up a cylinder of welding-grade argon. This we attached to the process station via a rubber hose. For reasons I do not understand, this experiment to make an argon-mercury ion laser failed. Others succeeded [4], [5]. But thinking that I had already proven the point with neon, I simply pumped out the discharge tube and refilled it with helium. It was Valentine's Day, February 14, 1964.

\section{AND THEN There WAS ARgON}

It took a couple of flushes with helium to turn the discharge from the blue of ionized argon to the violet-white of helium. The red and green outputs of the laser were again displayed on the laboratory wall through a transmission grating at the end of the optical bench. But now there was another line on the wall that appeared "turquoise" and with a brightness equal to that of the red and green mercury lines! A quick measurement with the 0.5 -meter scanning spectrometer in the laboratory gave the wavelength as $488 \mathrm{~nm}$ (with about $0.2-\mathrm{nm}$ accuracy). The time behavior was strikingly different. This blue line oscillated exactly with the current pulse, while the red and green mercury lines remained in the afterglow. Given the dubious purity of the welding tank and rubber hose filling system, it was not immediately certain that the line originated from argon. After the minutes it took to do the above measurements, I left Hodge in the laboratory to look after the laser (we were afraid to turn it off), and headed for the library downstairs at HRL. The MIT Wavelength Tables [6] listed a line at this wavelength, but without notation as to the source: Ar I (neutral) or Ar II (singly ionized). I could not lay my hands quickly on a decent reference for the second spectrum of argon. (I did not discover the excellent monograph by L. Minnhagen [7] in the Swedish journal Arkiv Physik until some months later.)

In about half an hour, I returned to my laboratory, where the laser was still running. At this point, we decided to flush the discharge tube a few more times with helium, and indeed, the blue 488-nm line gradually went away, leaving only the red and green lines of mercury. Then we reproduced it by going through the same process as before, with argon from the welding tank. We also noted that we could make the $\mathrm{Hg}$ II lines disappear by freezing out the mercury in a side-arm of the discharge tube 


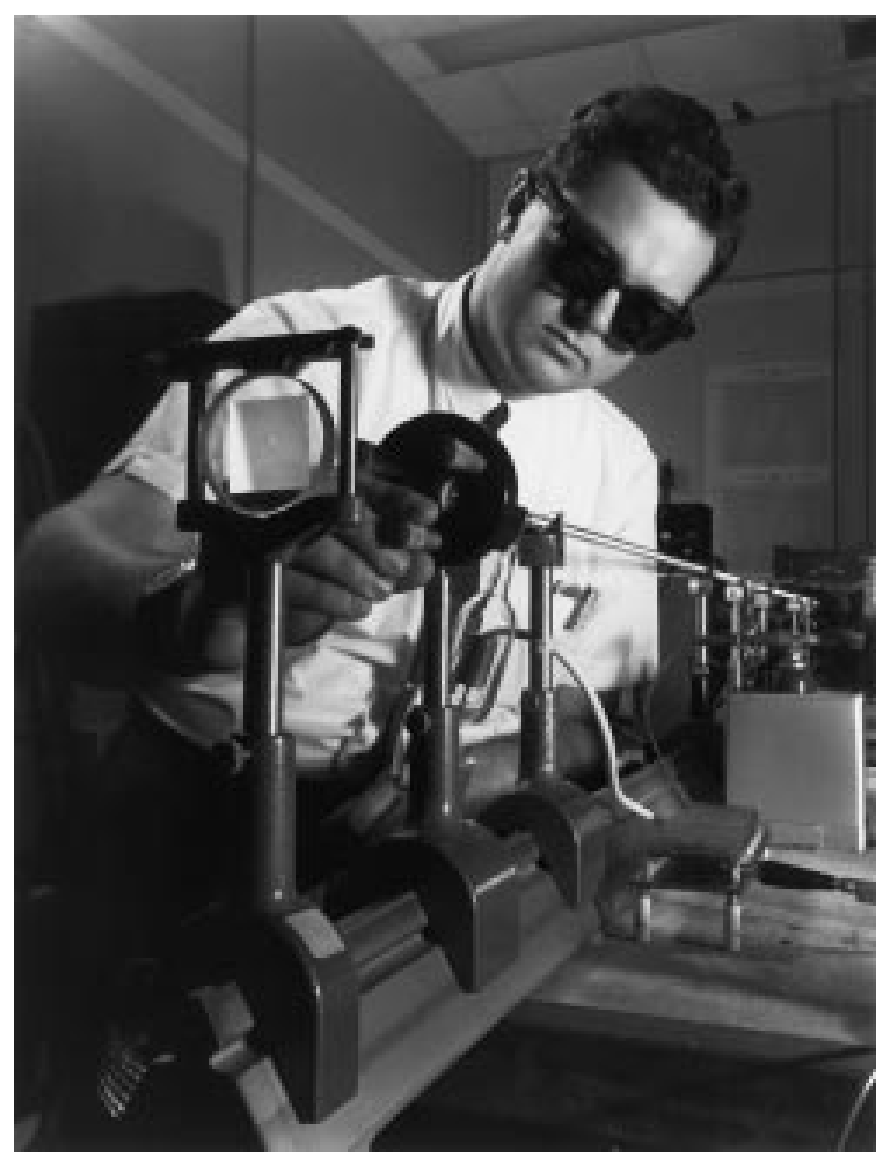

Fig. 2. The author and argon ion laser number two, February, 1964.

with liquid nitrogen. At this point, I went running through the hallways, dragging my supervisor, Donald C. Forster, and others down to the lab to see "the blue laser." By the end of the day, we had an order placed with the HRL glass shop for an identical tube, but with no mercury!

The new tube was ready in a couple of days, and we filled it with helium (mostly) and argon (just a little bit). To our surprise, we now had five wavelengths oscillating, from green $(515 \mathrm{~nm})$ to blue $(476 \mathrm{~nm})$, including the previously observed $488-\mathrm{nm}$ "turquoise" line. Evidently, the "contamination" from mercury had degraded the discharge conditions for the other four lines in the previous tube. All of these lines oscillated coincident with the discharge current pulse. The total peak power output was estimated on the order of $1 \mathrm{~W}$, with the discharge running $30 \mathrm{~A}$ current in 5- $\mu$ s pulses at 70 pps. Fig. 2 is another "A Boy and His Laser" photo, of this tube about a week after it was turned on for the first time. (Incidentally, the Smithsonian Institution called years later to see if "the first argon ion laser" was available for donation. We told them it was contaminated with mercury and we had thrown it away. They were uninterested in "tube number two.")

It was clear that we needed more accurate wavelength measurements than we could obtain with the 0.5-m scanning instrument in our laboratory. A 2-m photographic Bausch and Lomb (B\&L) spectrometer was available at the other end of the building. It was also clear that it would be difficult to move either the laser (attached to its process station) or the spectrometer. But this was a laser! We directed the beam out the lab door, down one hall, around a corner, down another hall, through another lab to a second hall, and finally into the room housing the B\&L instrument. The path used seven mirrors in all, attached to the metal walls with magnets or C-clamps, over 300 feet of total path length. Of course, we were trying to keep all this "quiet" until we could publish our results. We made the measurements after hours, with telephone contact from our laser lab to James K. Neeland running the B\&L spectrometer.

But of course the HRL management knew of our discovery. One of the HRL Department managers, Ronald Knechtli, had left for a technical meeting in Europe, and was visiting Thompson CSF Laboratories in France. We received a telegram from him stating that he'd seen a laser with red, green, and blue lines there in the laboratory of Guy Convert, and that we had better publish quickly! And this is indeed what we did.

It is now clear that ionized argon was "an idea whose time had come." I am aware of three independent discoveries of oscillation in ionized argon besides that at HRL. Convert and his coworkers at CSF were doing the same thing I was doing, adding argon to a mercury ion laser discharge. His initial publication in Compt. Rendus [5] appeared a week before my letter in Applied Physics Letters [8], [65], but he reported only the existence of a blue line, without a correct identification. He correctly identified the 488-nm line in a later publication [9]. The second independent discovery was made by Prof. William Bennett and his group at Yale University [10], who were looking at argon as an ion laser possibility on theoretical grounds, not as an additive to a mercury discharge. Their "sudden perturbation" excitation process is described in [10]. Bennett had submitted an earlier version of this paper to Applied Physics Letters, and it had the misfortune to "collide" with mine in the Editor's office. The editor rejected the Yale paper, citing mine as priority. Reference [10] is actually a second, more extensive, description of their work. The third independent discovery was made, appropriately enough, by W. Earl Bell, who was doing the same things that Convert and I were doing, attempting to find out how the helium-mercury laser really worked. Stanford Professor Robert L. Byer, then a new graduate student at Stanford, and a new employee at Spectra Physics, was given the task of identifying the blue line that Earl had found. Byer identified the lines, but my paper had just appeared, so Bell and Byer did not submit a formal publication [4]. As far as I know, I was the only discoverer to submit a patent disclosure on noble-gas ion lasers [11].

\section{AND Still More COLORS}

During the course of our "long-distance spectroscopy," we were able to coax ten total visible wavelengths out of singly ionized argon [8], and also 15 lines in singly ionized krypton and six lines in singly ionized xenon [12]. In addition, we had also recorded on the spectroscopic plates several lines that did not seem to belong to argon, krypton, or xenon, and this was a puzzle. In particular, there were four lines in the blue-violet region that were strong, and occurred on plates for more than one noble gas. I recall sitting in my living room at home and searching through the MIT wavelength tables, when it struck me that these four lines were from singly ionized oxygen! We had 
used oxide-coated thermionic cathodes in our discharge tube. The nickel cathode and filament assembly had been scavenged from worn-out pulse tubes, Eimac 4PR60's, the same vacuum tubes used in our pulser. To rebuild these cathodes, they were cleaned and then sprayed with a standard "oxide cathode" mixture of powdered barium, strontium, and calcium carbonates in a nitrocellulose binder. Under vacuum, the cathodes were heated to drive off the binder, then decompose the carbonates to oxides, and finally, liberate a monolayer of barium. This is a standard vacuum tube cathode, and HRL was well furnished with this technology. In operation, these cathodes give off a little oxygen as the barium evaporates. In a normal vacuum tube, this is collected by a chemical "getter" built into the tube. Here, the oxygen collected in the discharge and lased! And there were also nitrogen and carbon atoms, left over from the nitrocellulose and the carbonates, and these also lased as ions! We listed all these lines in a more extensive publication on 118 different laser lines we observed [13].

The laser wavelengths recorded on the photographic plates were measured under a microscope for an estimated accuracy of a few times $0.001 \mathrm{~nm}$. This actually proved critical in identifying one of the original ten argon laser lines $(502 \mathrm{~nm})$, which had a "logical but incorrect" assignment only $0.05 \mathrm{~nm}$ away from an "illogical but correct" assignment. These measurements were made by Arthur N. Chester and myself, usually after normal working hours. Chester was then a Howard Hughes Doctoral Fellow, assigned part-time to our group at HRL, with classes at Caltech during the day. He would check out the spectroscopic references at the Caltech library during the day, make copies, and then drive to HRL in Malibu for the evening. His major was theoretical high-energy physics, and I was an electrical engineer. Neither of us had any experience in practical spectroscopy, so we "learned on the job." I am certain that if a real spectroscopist could have looked over our shoulders, we would have provided no end of amusement. We had recorded the iron spectrum on each plate (from a discharge between two nails near the slit of the B\&L spectrometer), along with the laser lines. We worked our way across the iron spectrum, identifying each line from the tables in my high school copy of the Handbook of Chemistry and Physics [14]. Then we would interpolate the laser wavelength between the nearest iron lines. Since iron is such a "rich" spectrum, we could make this measurement very accurately. But also because it is such a "rich" spectrum, we had to identify scores of iron lines between each laser line. This took some time. A year after we did this, I discovered, tucked away on a shelf in the HRL library, the Vatican photographic atlas of the iron spectrum, all conveniently broken into segments intended to match your spectrographic plate so you do not have to identify any iron lines, just match the pictures!

One group of lines remains a puzzle, even to this day. When we went to higher and higher pulsed currents in xenon, we noted some strong lines in the blue and green [13]. These were not to be found in the spectroscopic literature as far as we could determine. I was visiting Washington, DC, in July 1964 and stopped by the National Bureau of Standards (NBS) to visit Charlotte Moore Sitterly, who was widely known for her publications of atomic and ionic energy levels. [15]. I had used the references from the 1930s by Curtis J. Humphreys at NBS for the identifi-

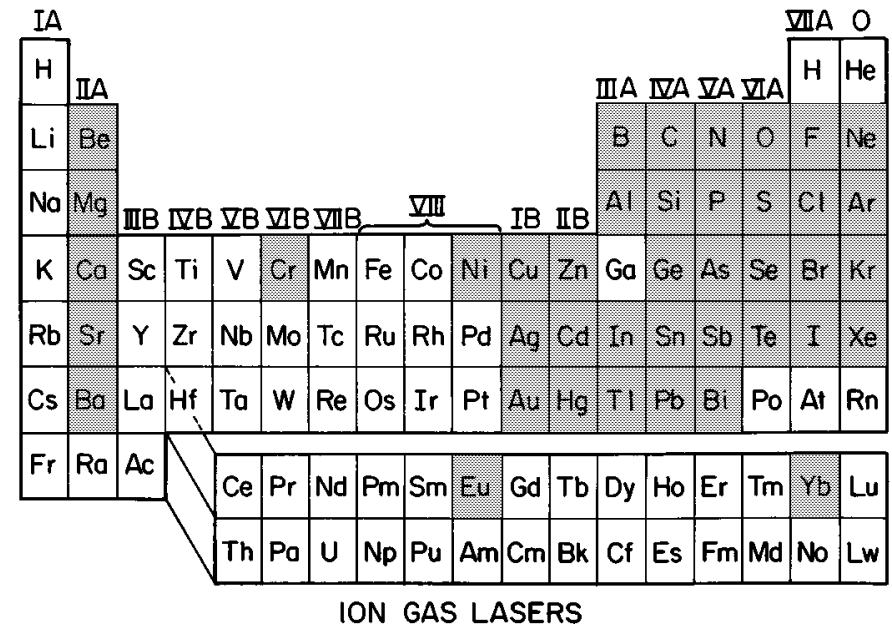

Fig. 3. Periodic table of the elements, with those that work as ion lasers shown shaded (as of 1982).

cation of lines in Xe II and Xe III [16]-[18], and I thought that he might have left some unpublished lists with Dr. Sitterly. As it was, she did not have any listings for the unknown xenon lines we had observed, but said, "Oh, Curtis took all his notes with him when he left for the Naval Ordnance Laboratory facility in Corona, CA." When I returned to California, I telephoned him, and he confirmed he had observed all the xenon wavelengths we had seen lase, but that he had not published them, since he could not identify them. Many other groups have reproduced these laser lines and puzzled over them (see [3, Section 2.2.3] for references to work through 1979). But no one has identified them beyond the initial guess that they are from "Xe IV" the spectrum of triply ionized xenon. Even a laser product producing these lines at $2 \mathrm{~W}$ average power was marketed [19]! Later, more "Xe IV" and possibly "Xe V" and "Kr IV" lines in the vacuum ultraviolet were added to this list of puzzles by Marling at the Lawrence Livermore National Laboratories [20].

By mid 1964, there were many researchers working on ion lasers with all sorts of ions. Since then, almost everything that is a gas at room temperature or can be vaporized easily, or can be produced by dissociating a gas molecule, or can be sputtered into a discharge, has been made to lase as an ion. These elements tend to cluster on the right-hand side of the Periodic Chart, as seen in Fig. 3. Art Chester and I collected what had been reported by ourselves and others by mid 1964 [21], again in 1971 [22], and again in 1982 [23]. The excitation mechanisms for various ion lasers, as they were understood in 1979, were described in [3, Sections 2.2 and 2.4], which also has about 350 literature citations for ion lasers through 1979 . The most recent listing of ion laser wavelengths is [24]. Table I gives a time line for the discovery of the various gaseous ion lasers indicated in Fig. 3.

Given the hundreds of wavelengths originating from scores of ions, it may seem surprising that only the noble gases, particularly argon and krypton, saw extensive commercial application. Neon and xenon among the noble gases were worth a try in the early days, but both discharges proved to be tough to tame, and tended to tear up the walls of the discharge tube structure. And they offered little advantage over argon and krypton in power output or wavelength selection. The only other ion laser that re- 
TABLE I

TIME LINE FOR DISCOVERY OF GASEOUS ION LASERS 1963-1980

\begin{tabular}{ll}
\hline 1963 & $\mathrm{Hg}$ \\
$1964 \mathrm{Ne}, \mathrm{Ar}, \mathrm{Kr}, \mathrm{Xe}, \mathrm{Cl}, \mathrm{I}, \mathrm{O}, \mathrm{N}, \mathrm{C}$ \\
$1965 \mathrm{~F}, \mathrm{Br}, \mathrm{S}, \mathrm{Se}, \mathrm{P}, \mathrm{As}, \mathrm{Si}, \mathrm{Zn}, \mathrm{Cd}$ \\
$1966 \mathrm{Te}, \mathrm{Sb}, \mathrm{Ge}, \mathrm{Sn}, \mathrm{Pb}, \mathrm{B}, \mathrm{In}, \mathrm{Ca}$ \\
$1967-$ \\
$1968 \mathrm{Bi}, \mathrm{Sr}$ \\
$1969-$ \\
$1970 \mathrm{Yb}, \mathrm{Ba}$ \\
$1971 \mathrm{Mg}$ \\
$1972-$ \\
$1973 \mathrm{Tl}, \mathrm{Ag}, \mathrm{Eu}$ \\
$1974 \mathrm{Cu}$ \\
$1975 \mathrm{Be}$ \\
$1976 \mathrm{Au}$ \\
$1977 \mathrm{Al}$ \\
$1978-$ \\
$1979 \mathrm{Ni}$ \\
$1980 \mathrm{Cr}$
\end{tabular}

ceived serious commercial development was the cadmium ion laser, originally discovered by William T. Silfvast [25] during his doctoral research at the University of Utah, and developed later when he joined Bell Laboratories [26]. This is largely due to the more benign nature of the discharge conditions that optimize the laser's performance. The helium-cadmium ion laser operates more in the regime of the helium-neon laser discharge than the argon ion laser discharge. See [3, Sec. 2.4] for a discussion of mechanisms and a guide to the literature.

The chemical reactivity of many materials precludes their use in a practical commercial product. This is especially true of the Group VIIA halogens, which have many lasing wavelengths in the UV and visible, as well as the Group IIIA through VIA elements. Some of these are solid at room temperature, but can be obtained from gaseous molecules, for example, $\mathrm{S}$ from $\mathrm{SF}_{6}$, [27] or $\mathrm{P}$ from $\mathrm{PF}_{5}$ [28]. Other solid materials can be sputtered in hollow-cathode discharges, such as $\mathrm{Ni}, \mathrm{Cu}, \mathrm{Ag}$, and $\mathrm{Au}$ [29]-[32].

There are fewer ion lasers on the left-hand side of the periodic chart. Only the Group IIA elements lase as ions. The Group IA elements are conspicuous by their absence. Given the ease with which sodium can be used in a discharge, it is puzzling why no ion laser lines have been seen from the various ions of sodium. The spectrum of singly ionized sodium, Na II, is similar to the spectrum of neutral neon, $\mathrm{Ne}$ I, and that of doubly ionized potassium, K III, should be similar to that of singly ionized argon. Perhaps it is the lower ionization potential of the neutral $\mathrm{Na}$ or $\mathrm{K}$ that keeps the electron temperature in the discharge lower than in the corresponding noble-gas discharges, and thus hinders the electron-collision excitation of the ionic levels. In the 1960s,
HRL was engaged in the development of electric space propulsion using cesium ions. We had a lot of cesium metal readily available, so it was a natural experiment to put some in a discharge tube and excite it under the same conditions as a simple pulsed argon ion laser. We used an existing glass discharge tube. Unfortunately, the cesium tended to disappear quickly into the glass walls of the discharge tube! We decided such a laser would not be practical, even if we were successful, so we abandoned the effort.

I have always considered the discovery of still more ion lasers a bit of unfinished business. In 1965, Art Chester and I considered how easy it would be to make ionized radon lase. The only thing that stood in the way was the HRL management, who refused to consider the required "hot lab." (Radon has a half-life of four days, so you have to work quickly!). The demonstration of laser oscillation on the higher ionization states of the right-hand side of the Periodic Chart should only require higher discharge currents. Likewise, I think lasing on the ions of Group IA elements is only a matter of technical persistence. Even the metals of Group IIIB through Group VIIIB, and the refractory metals of group VIII should produce some laser action, provided you can sputter the atoms into the discharge. But the biggest obstacle to discovering new ion laser lines is likely disinterest! Anything new will just be a laboratory curiosity. The field has moved on, with argon and krypton serving in the trenches for 35 years, waiting for a more efficient diode-pumped solid-state laser to displace these monsters from the technical workplace. I believe there is room for an army of graduate students to discover new ion lasers, but I also believe they would have trouble finding employment after graduation!

\section{Continuous Operation}

Ion lasers would have remained a laboratory curiosity if they could be operated only as pulsed discharges. However, continuous operation is possible and practical, although that fact was not evident at first. My early pulsed tubes used very low pressures of argon, typically 50 mtorr in a 3-mm-diameter discharge tube. Discharge currents were tens of amperes at first, then 100-200 A or more. The voltage drop along a 1-m tube was of the order of $1000 \mathrm{~V}$. So initially, we were dealing with $10-\mathrm{kW}$ pulses at the minimum. This posed much different technical problems than a typical helium-neon discharge.

The first continuous operation was obtained by Eugene I. Gordon and Edward F. Labuda at Bell Telephone Laboratories, and published by Gordon, Labuda, and Bridges [33]. The sequence of events leading up to the publication are a bit unusual, and are as follows: I had discussed my Hg II laser results with Gordon in early February on a visit to BTL, as mentioned above, and I met him again at an IEEE Committee meeting Easter week of March 1964. At that meeting I gave him a preprint of both my argon paper [8] and my krypton/xenon paper [12], and we discussed my results. I noted that argon lased with the current pulse whether in pure argon, or argon with neon or helium as a buffer gas, suggesting direct electron excitation was a mechanism. I also opined that argon might be a candidate for continuous operation, but that the power required would be much too high (exhibiting my "helium-neon" state of mind). 
Gordon had more faith than I had! A week or so after the meeting, I received a telephone call from Gordon, saying that they had argon oscillating continuously, with about $1 \mathrm{~A}$ in a small-bore discharge tube. The output was less than a milliwatt but was increasing rapidly with current up to the maximum the tube could handle. Gordon generously volunteered to add my name to the paper he and Labuda were writing, but I told him I would like to contribute more to the work, and that we had a much bigger power supply at our disposal. Gordon and Labuda started writing, and Hodge and I started making a suitable tube at HRL. At first, we tried an air-cooled fused-silica discharge tube, but the discharge "got away from us," with a spectacular display of a traveling fireball that went up and down the length of the tube, destroying it utterly in seconds. The next attempt took a few days to build, and resulted in "tube C" in the publication. This tube was a water-cooled fused-silica tube, $2.5 \mathrm{~mm}$ in inside diameter and about $20 \mathrm{~cm}$ long, and it would survive up to $15 \mathrm{~A}$ or so of discharge current. We obtained about 50-mW output total on the argon blue-green ion lines. But we could get $80 \mathrm{~mW}$ out each end on the blue-green lines of krypton, and similar outputs on the lines of xenon. The draft of the paper went back and forth by mail over a few weeks, to collect the measurements on "Tube A" and "Tube B" at BTL, and "Tube C" at HRL, and then off to Applied Physics Letters. By another unfortunate coincidence, the paper by Bennett and his group on "Quasi-CW" operation of argon [10], the extension of their previously rejected paper that had collided with my original argon paper, now collided with our CW paper in the APL Editor's office. This time, the Editor (wisely, in my opinion) decided not to reject the Bennett group's paper again, and the two were published back-to-back in the May issue of APL. From time to time, people have asked me how it came to be that groups at Bell Labs and Hughes "cooperated" in the demonstration of the first CW argon ion laser. The above is the story.

\section{HOW ION LASERS WORK}

It is impossible to give all the details in one paper. Instead, I will attempt to summarize briefly what we know about argon ion laser mechanisms, most of which we learned in the last half of the 1960s. For a guide to the literature about other ion lasers, see [3, Sections 2.2 and 2.4], for example, or the extensive reviews by Dunnand Ross [34] and Davis and King [35].

Research in the early years was directed at determining the pathways by which the upper laser levels were excited and the lower laser levels destroyed. Closely coupled to this was research to determine the gas discharge parameters, such as electron temperature, ion temperature, electron density, and the atomic parameters of collision cross section, transition probabilities, etc. The goal was, of course, to make a mathematical model that would predict the observed behavior with diameter, length, current, pressure, etc. It is fair to say we did not completely succeed, although we know enough to make successful ion lasers, which is the engineering goal in any case.

The first pathway proposal was published by Bennett et al. [10], and is illustrated in Fig. 4(b). They proposed that the upper laser level was excited from the argon ground state (37

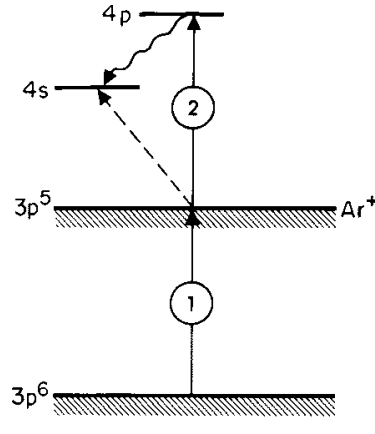

(a)

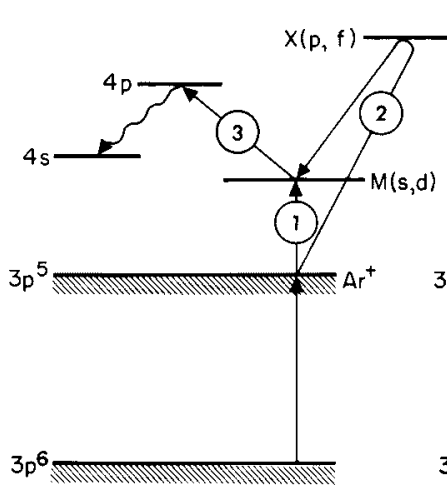

(c)

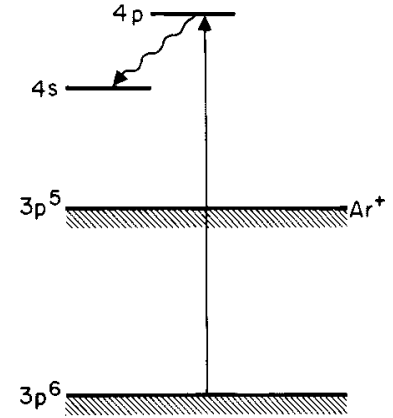

(b)

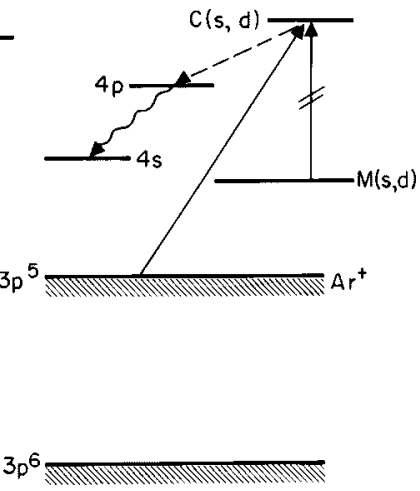

(d)

Fig. 4. Four different proposed excitation pathways for argon ion laser upper levels.

$\mathrm{eV}$ ) by collision with single high-energy electron and that the preferred upper level would be the $4 p^{2} \mathrm{P}_{3 / 2}$ level, based on a "sudden perturbation" calculation. This would predict that the 476-nm line of Ar II would oscillate. In fact, this is the strongest line when a pulsed discharge is operated at very low gas pressure, the condition which produces a high value of $\mathrm{E} / \mathrm{p}$ (electric field to gas pressure ratio) that yields high electron energies in a discharge. However, it does not explain why the 488 and 515-nm lines oscillate, much less why they are the strongest lines in the usual operation of the $\mathrm{CW}$ argon ion laser, at much smaller $\mathrm{E} / \mathrm{p}$.

The "two-step" scheme illustrated in Fig. 4(a) was first proposed by Labuda, Gordon and Miller [36], based on the observation that well above threshold the laser output power varies as the square of the discharge current, suggesting that two successive electron collisions were involved. The electron energies implied by Fig. 4(a) are still pretty high compared to the electron temperatures later measured for typical argon ion laser discharges, however (a few electronvolts). One can argue that step 1 may, in fact, be a very complicated series of substeps involving much lower electron energies, ultimately resulting in having the ion ground state population proportional to the discharge current (which is really required by the overall condition of charge neutrality for the discharge in any case). But step 2 would require electron energies greater than $20 \mathrm{eV}$. In fact, typical collision cross sections for electric-dipole-allowed transitions may peak as much as $100 \mathrm{eV}$ above the threshold energy. Even worse, the ion ground state is a $3 \mathrm{p}^{6}$ state and has the same parity as the $4 p$ upper laser levels, thus making step 2 a "forbidden" process. Of course, no process is really forbidden, but the cross section 
should be much lower. However, for forbidden transitions, the cross section typically peaks just above threshold, not $100 \mathrm{eV}$ above threshold, thus favoring $20 \mathrm{eV}$ electrons, not $120 \mathrm{eV}$ electrons (see [37] for actual measurements of these cross sections).

The scheme illustrated in Fig. 4(c) is a refinement by Labuda et al. [38]. The "first electron" is again the sum of the processes that create an ion ground state proportional to the discharge current. Labuda et al. measured large ion metastable level populations that are closely coupled to the ion ground state due to the rapid electron collisional creation and destruction processes. Thus these metastable level populations also are proportional to the discharge current. Some of these metastable levels are connected to the $4 p$ upper laser levels by allowed transitions requiring only $3-\mathrm{eV}$ electrons for excitation. This is the "second electron" that results in the square law variation with discharge current.

The above model seemed to explain the observations, until Robert I. Rudko, a graduate student of Prof. C. L. Tang at Cornell, measured the spontaneous radiation intensities of all the transitions cascading into the $4 \mathrm{p}$ upper laser levels and all those coming out of the $4 \mathrm{p}$ levels, in a nonlasing discharge. Rudko and Tang concluded that about $50 \%$ of the population of the $4 p$ levels resulted from this cascade from higher lying states, as indicated in Fig. 4(d) [39]. A. Stevens Halsted and I repeated this measurement for one of our laboratory tubes, and concluded the percentage was about $30 \%$ [40], not as great but still a very significant fraction. The conclusion was that all the processes indicated in Fig. 4 contribute, with relative contributions changing according to the particular discharge geometry and conditions.

Many measurements and calculations of the plasma conditions in argon ion laser discharges were made early on, especially by Gordon's group at Bell Labs, and Sobolev's group at the Lebedev Institute [41], as well as the group at HRL. Reference [3] gives a guide to the extensive literature from these groups and others. A short summery of plasma characteristics is given in [42], by Chester, Halsted, Parker, and myself. The actual numbers vary with discharge geometry, operating pressure and current, but ballpark figures for a smaller laser are:

Electron temperature 2-3 eV (23 000-35 000K);

Ion temperature $0.2 \mathrm{eV}(2300 \mathrm{~K})$;

Gas temperature $0.15 \mathrm{eV}(1700 \mathrm{~K})$;

Electron density: a few $\times 10^{13} \mathrm{~cm}^{-3}$ (plasma frequency of $50 \mathrm{GHz}$;

Neutral density: a few $\times 10^{15} \mathrm{~cm}^{-3}$

Those familiar with discharge physics will recognize that experiments on plasmas with these parameters are definitely not easy. There was clearly a relationship between the ability to do such experiments and the engineering of practical ion laser discharge techniques and materials. In this case, scientific research and engineering development went hand in hand.

To make matters worse, such discharge parameters result in strong "pumping" of the gas in the discharge by ion drift (toward the cathode) and electron collision momentum transfer (toward the anode). Gas pressure gradients can develop in either direction, depending on the discharge current, and these can also be unstable. Gordon and Labuda were the first to recognize this problem, and also provided the answer in a "gas return path" from one end of the tube to another, outside the main gas discharge column to equalize the gas pressure [43]. At HRL, Halsted made extensive measurements of gas return path parameters [40], [42] and Chester, then in Gordon's group at BTL did likewise [45]. However, the problem is not as simple as equalizing the pressure. Experiments made during the course of developing a high-power UV ion laser [44] indicate that fully equalizing the pressure between the active region and the electrode regions is not a good thing; instead, the gas flow geometry must equalize the pressure in the two electrode regions, but promote a differential between the active (small diameter) bore region, and the electrode regions. Modern commercial disk bore ion lasers have carefully controlled gas flow geometries, and these are usually proprietary with each manufacturer.

\section{ARGON ION LASER ENGINEERING}

\section{A. The Pulsed Era}

Hughes was anxious to get some publicity for the discovery of the argon ion laser, and the first opportunity we had to exhibit it was at the Hughes Corporate booth at the July 1964 American Institute of Aeronautics and Astronautics (AIAA) show in Washington, D.C. This was hardly the ideal place to exhibit a new laser, but it was the first up. Robert Hodge and I built a small pulsed ion laser for the show. The laser output was about $1 \mathrm{~W}$ peak, and about $1 \mathrm{~mW}$ average over the blue-green argon lines. Few visitors to the booth had a clue what they were seeing. The typical question was "Where's the ruby?" The next opportunity we had for an exhibit was the IEEE WESCON show in Los Angeles in August 1964. We set up the same laser for a much more technically appreciative audience, and got a lot of attention. Unfortunately, we also received some unwanted attention from the National Radio Company booth next to the Hughes booth. National was exhibiting their latest communications receiver, and our unshielded pulser wiring, which had radiated unnoticed at the AIAA show (largely devoid of electronics exhibits) was now blasting the receiver next door! We were off the air for a day, shielding everything, but returned the next day with the RFI gone.

This small pulsed argon ion laser was the basis for a "product" from HRL. We had so many requests for a blue laser from inside HRL and elsewhere at Hughes, that Hodge and I decided to engineer a version suitable for manufacture. We handbuilt several of these units in 1964 as the HRL "Model 40" before the Hughes Electron Dynamics Division (EDD) took over the effort as the Hughes "Model 3040H" in a much classier-looking package. These small pulsed tubes were originally very short lived, since the discharge sputtered the fused-silica walls rather badly, especially in the "throat" region, and the sputtered material "buried" the argon gas. Thus the 50 mtorr of argon gas fill would be gone in 100 hours or so of operation. With Hughes EDD, we developed a cheap gas refill system, consisting of measured "doses" of argon sealed in glass ampoules, contained inside a soft copper tubular appendage. When the laser "went dry," you could break one of these ampoules by squeezing the copper tube with a pair of pliers. This may seem pretty crude, but it is no different in principle from the electronically controlled valve "burp" system still used in commercial argon ion lasers! 
Given the short life of our tubes, you can imagine our enthusiasm for a customer that approached us in 1966 with a requirement for an argon ion laser that "only needed to operate for a single pulse." The folks at Los Alamos wanted us to build a pulsed laser for instrumentation in an underground nuclear test. They needed $10 \mathrm{~W}$ or more output for a single $50 \mu$ s pulse. Hodge and I thought this would be a piece of cake, so we took the job and built a longer, larger diameter pulsed tube. Los Alamos ordered four tubes, so they could do some life testing in the lab and have spares. They developed their own "high reliability" pulsed power supplies. Some months later, Hughes EDD decided to "productize" this more powerful laser as the model $3041 \mathrm{H}$. Still later, we received a panic phone call from Los Alamos. They had "life tested" all four lasers, and now they were all used up, gas ampoules and all. We referred them to A. Gene Peifer at EDD to work out a "loan" of the $3041 \mathrm{H}$ prototype. After all, what could go wrong? The laser was to be located safely in the surface instrument shack. Unfortunately, this was one of those tests that did not quite go as planned, and the "test" swallowed the $3041 \mathrm{H}$ prototype. Los Alamos had to buy that fifth laser after all.

\section{B. CW Argon Ion Laser Engineering and Applications}

Of course, the pulsed ion lasers were only stopgap devices, to serve niche applications and to act as standins for the real challenge: a practical $\mathrm{CW}$ ion laser. In that, we were truly in at the beginning. Even before our CW paper [33] appeared, our colleagues at the Hughes Aerospace Group in Culver City, CA, knew about our results and came to Malibu for a visit. They had an application in mind that required "high" $\mathrm{CW}$ power in the visible. A year before, Perkin-Elmer Corporation had developed a line-scanning night reconnaissance system using a "heroic" 100-mW helium-neon laser, two 2-m discharge tubes in a folded path. In such a system, the laser beam is directed downward, and a high-speed rotating mirror scans the beam from side to side across the flight path. The aircraft motion supplies the scan along the aircraft track. The received reflected light intensity is recorded on film as "video" with a similar raster scan, and the result is a long strip map of the ground overflown by the aircraft, just like a daytime strip camera photo. A history of the Perkin-Elmer line scanning systems is given in [46]. The Hughes group was very interested, but concluded that $100 \mathrm{~mW}$ of red light was not really enough and that there was no further development possible for the helium-neon laser. Thus, when we had demonstrated more than $100 \mathrm{~mW}$ of blue-green output, they decided they should now develop a similar system.

Our first joint argon laser objective for the fall of 1964 was 200-mW output in a package rugged enough to fly. By July, we had over $200 \mathrm{~mW}$ out of a simple water-cooled fused silica. Of course, now that the systems group was serious, they were building additional margin into their design, and asked for 400 $\mathrm{mW}$. Since the output power seemed to be increasing as the square of the discharge current, it seemed reasonable to us that we could meet this objective, too, and we did. But when they upped the ante to two watts, we decided it was time to have a talk with their optical designer! It turned out that he was not familiar with Gaussian beams, so he had chosen to expand the beam and chop off the tails, so he could work with a more familiar "top hat" transverse distribution! I recall we had to "educate" him about the inherent merits of Gaussian beams. But we also gave the systems people their two watts.

It became clear that fused-silica walls in the discharge tube were not going to allow an indefinite increase in the discharge current, and the sputtering by ions accelerated across the discharge wall sheath (10 to $20 \mathrm{eV}$ ) resulted in severe erosion and gas cleanup, even at the $\mathrm{CW}$ operating pressure of about 0.5 torr. Since our department at HRL, headed by Donald C. Forster, also did research and development in millimeter-wave vacuum tubes [47], it was only natural to feel that a proper ion laser should be an all-metal-ceramic device. We undertook the design of such a device in the summer of 1964, in parallel with the push toward higher powers using fused-silica tubes made in the HRL glass shop. Most metal-ceramic vacuum tubes use polycrystalline aluminum oxide (alumina) as the ceramic, and this is where we began. It was not long before we were breaking alumina discharge tube bores right and left. Unfortunately, when the discharge strikes, the bore has to conduct 200-400 W of heat per centimeter of length, radially outward toward the coolant jacket. We originally thought thermal shock was the culprit, but later we concluded that it was stress caused by the thermal gradient in the poorly conducting alumina.

We spent months trying to improve the design, and learn how to "turn the discharge on slowly." Still, the end result was invariably broken tubes. The date for the first flight test of a prototype Hughes system was fast approaching, so we stuffed a laboratory-type fused-silica laser (complete with an argon bottle and a refilling valve) into the box the system's people had built for us, and hoped for the best. The system was flown in 1965 in the bomb bay of a B-47 from Wright-Patterson AFB, and performed beautifully. I no longer have the imagery from those tests, but I do recall that we caught the image of a military service mechanic asleep spread-eagle on the tarmac beside his plane one night overflying the flight line. To make our nights even less restful, in the middle of this test program, the Air Force brass decided that all the WPAFB test pilots needed landing practice, and the B-47 with our system aboard was chosen as the training aircraft. Our "fragile" fused-silica laser did touch-and-go's at WPAFB for two weeks... and survived!

While we were engaged in developing a "flight-qualified" $\mathrm{CW}$ ion laser, others were doing the same for commercial sales. As far as I can tell, Raytheon was the first to advertise a CW argon ion laser for sale in late 1964. I have a brochure and letter in my file, dated February 1965, offering the Raytheon LG-12 for $\$ 27500$. Their design used a glass-blown fused-silica discharge tube and produced $1 \mathrm{~W}$. The operating life was guaranteed for 100 hours, the laser head weighed $80 \mathrm{lbs}$, and the power supply $600 \mathrm{lbs!}$

During 1964 and 1965, I had several telephone conversations with Earl Bell at Spectra Physics, who was engaged in their CW argon ion laser development project. Mostly, we commiserated on approaches that did not work. I told him of the thermal shock problems with standard alumina, and he told me of his problems getting a straight bore of beryllium oxide (beryllia). This negative view of beryllia was unfortunate for both of us, since we 


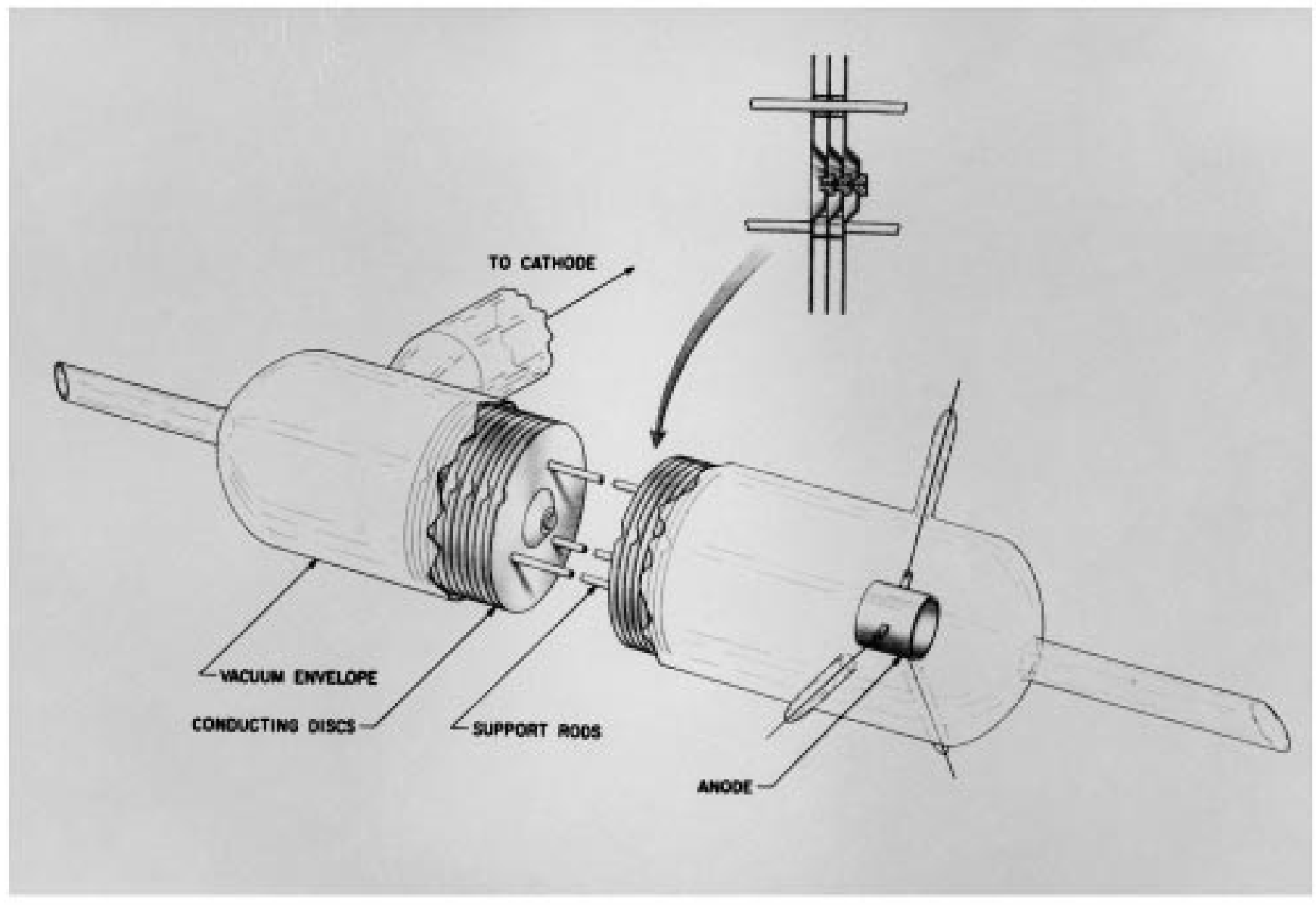

Fig. 5. Schematic view of a segmented metal-bore ion laser discharge tube developed at Bell Telephone Laboratories in 1965 (from [36]).

both later made successful beryllia-bore discharge tubes, but for 1964-1965, we avoided the material.

A major breakthrough in $\mathrm{CW}$ discharge engineering was made in 1965 by Labuda, Gordon, and Miller at Bell Labs [36]. While it seems counterintuitive, you can make the walls of the discharge tube out of metal, provided you break the length of the discharge tube into short electrically floating segments. Labuda made a design with short molybdenum tubes, supported in the center of disk-like cooling fins, as shown in Fig. 5. The assembly of disks was then fitted into a large-diameter fused-silica vacuum envelope, with the fins radiating heat through the envelope.

Fresh from his Ph.D. at Stanford, A. Stevens Halstead joined HRL and the ion laser research and development activity. Shortly thereafter, we adapted Labuda's design to use molybdenum "slugs" contained in a one-inch i.d. alumina vacuum envelope. Thus we would have our all-metal-ceramic tube, without exposing the alumina to the thermal shock from striking the discharge. But we were not home free, since deposits of sputtered molybdenum "shorted out" the slugs at the alumina wall, thus limiting operating life. The search for a lower sputtering rate material lead naturally to tungsten, but fabrication of machined shapes in tungsten is not easy. HRL had experience in machining precise tungsten shapes from sintered porous tungsten, with the pores filled with copper as a machining lubricant. The copper is boiled out in a vacuum furnace after machining. We tried "slugs" made of this material, which proved to be low sputtering indeed. Unfortunately, some copper always remained in the pores, and gradually evaporated out and deposited on the envelope walls, again shorting out the discharge.

About this time, James R. Fendley, Jr., and Karl G. Hernqvist at RCA Laboratories reported an argon ion laser made with graphite "slugs" that had even lower sputtering yield than tungsten [48]. This we also tried, and found that the graphite was a low sputtering material as advertised, but it had a tendency to flake off powder with time. While this might not have been a problem in a commercial laboratory tube sitting on a workbench (RCA and later Coherent sold quite a few), it was not going to be suitable for an airborne-qualified laser! We tried a number of variations including pyrolytic graphite and pyrolytic graphite overcoated with CVD tungsten. None of these bore materials and configurations worked very well. All of the above engineering developments are documented in a series of Air Force reports, and summarized in two final reports [40], [49].

The next breakthrough in ion laser engineering was the discovery by Huchital and Rigden that the discharge walls, whether continuous insulating material or metal segments, could be replaced with a series of thin metal disks with holes [50]. Of course, this only worked if a strong magnetic field was used to confine the discharge, but such fields were already used to improve the power output. With this geometry, low 


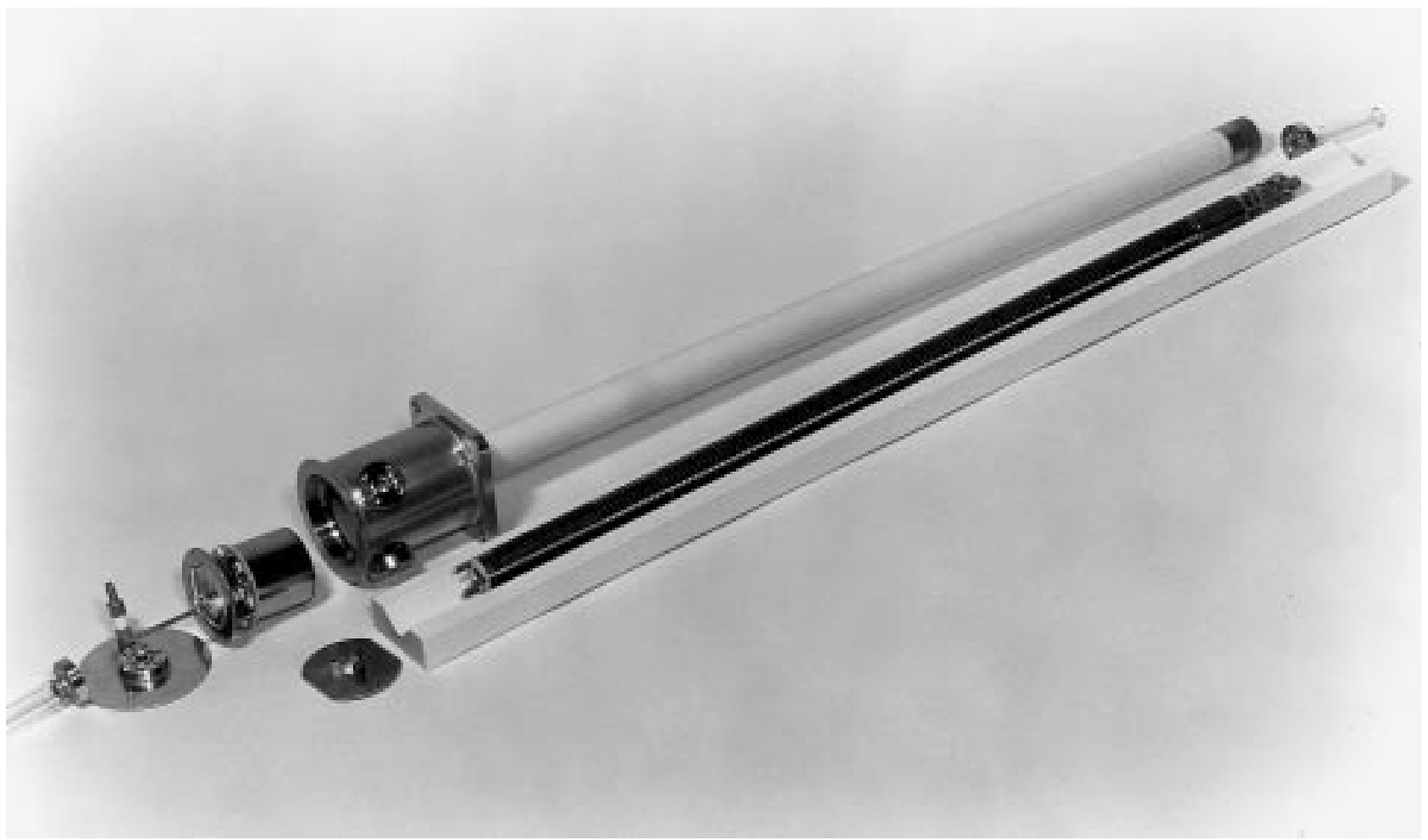

Fig. 6. Photograph of a metal/ceramic argon ion laser discharge tube using radiation cooled tungsten disks, prior to assembly. This tube was developed at the Hughes Research Laboratories for the AN/AVD-3 night reconnaissance system, 1967-1970.

sputtering tungsten could now be used, since very little machining is required to make a disk with a hole in it. This was the structure we adopted for the airborne-qualified laser for the follow-on Hughes development night reconnaissance system, the AN/AVD-3. A photo of the discharge tube parts prior to assembly is shown in Fig. 6, with the series of thin tungsten disks (about one inch in diameter) stacked for insertion into the alumina vacuum envelope. The metal can at the left contained the thermionic cathode. This system was successfully flown in 1968-1970 with excellent results, but it was never funded for production. (The Air Force did not like the idea of modifying RF-4's to route several gallons per minute of laser coolant through bulkheads from the camera compartment in the nose to the heat exchangers in the wing fuel tanks.) With the demise of this application as a driver for development, we ended the ion laser work at HRL. Halsted left HRL to join the Hughes Electron Dynamics Division and continued with the development of a third-generation airborne argon ion laser using a beryllia-bore discharge tube for the Air Force Materials Laboratory (AFML) at WPAFB. But since there was no longer a system application, that effort ended with the delivery of 13 lasers to AFML [51]. That design eventually became the first Hughes commercial CW argon ion laser product, the Hughes EDD 4066H, in 1975. However, EDD withdrew from the argon market completely about 1976.

\section{HEROIC NUMBERS}

No report on the early days would be complete without mentioning the winners in the power race. Many groups, including HRL, made it to the 10-20-W level by 1966 , but the overall
U.S.A. winner was Jim Fendley and J. J. O'Grady at RCA, who delivered a 100-W CW output laser to the U. S. Army [52] in 1970. Their tube design used a $2.5-\mathrm{m}$ stack of radiation-cooled graphite disks, with 6.4-mm diameter holes and a discharge current of $90 \mathrm{~A}$. The overall international winner is V. I. Donin and his group in the Soviet Union, who reported a 500-W CW output argon ion laser in 1973 [53]. This tube was $16 \mathrm{~mm}$ in diameter and $1.5 \mathrm{~m}$ long, and ran at 390-A discharge current with an efficiency of $0.2 \%$. The walls used alumina coatings on aluminum disks that were stacked and directly water cooled. As far as I know, this is still the record for a gaseous ion laser.

\section{Some IdeAs That Did Not Work Out}

In 1965, Earl Bell reported a novel excitation method for pulsed ion lasers. He used the discharge bore and a gas return path as a rectangular-shaped one-turn secondary winding of a ferrite core transformer [54]. This had the advantage of being an "electrodeless" discharge, eliminating any problems with the anode and cathode of a conventional dc discharge (which also meant that chemically active elements like the halogens could be used in the discharge). When he ran into problems with beryllia in his CW laser development, he extended this "one-turn" secondary to $\mathrm{CW}$ lasers, using high-power $\mathrm{r}-\mathrm{f}$ at $41 \mathrm{MHz}$, air-core coupled with a few turns of heavy copper tubing. This was the basis of Spectra Physics' first commercial argon ion laser [55]. However, this product only lasted a year or so due to insufficient operating life. While the Brewster's angle windows were located in side arms away from the main "turn" of the discharge, there was sufficient $r-f$ floating around to produce mild discharges in these side arms. Initially this was deemed to be a good 
thing, to have the discharge "wash" the windows of any contamination. Unfortunately, it also ion-etched the windows and turned them into negative lenses in a couple of hundred hours, so that the optical cavity would become unstable [56]!

Argon ion lasers have been excited by several different means, ranging from microwave-driven discharges [57], microwave cyclotron resonance [58], and $Z$-pinch discharges [59]-[61], among others. Even a theta-pinch fusion machine was used to make an argon ion laser. Unfortunately, the power into the pinch had to be throttled to ridiculously low powers to make the conventional Ar II and Ar III lines lase. At its "normal" fusion-research level, the emission (nonlasing) was all in the short wavelength ultraviolet on unidentified lines from very high ionization states of argon [62]. For the last 35 years, the simple dc discharge has been the workhorse of commercial argon ion lasers.

The engineering development of dc discharges for ion lasers is fraught with ideas (amusing in retrospect) that did not work out, and we recount a few here.

In our frustration with thermal shock in alumina as a discharge bore material in 1964, we made a laser discharge tube with a boron nitride $(\mathrm{BN})$ bore, press fit into a water-cooled copper vacuum jacket. Solid boron nitride, made from hot-pressed BN powder, seemed an ideal material, since it was very resistant to thermal shock and easily machinable. It lived up to our expectations in these regards. Unfortunately the discharge would erode the powdered material in a few tens of hours, and the powder would be electrostatically suspended in a small "cloud" on the optical axis, thus shutting off the optical path through the tube. We only built one.

During early environmental testing of the laser for the AN/AVD-3, we discovered that the laser output would disappear at high altitudes in the test chamber. It could be regained by realigning the mirrors. The problem was that we had oriented the Brewster's angle windows on the two ends of the tube to "face up," since this made them easy to clean in the laboratory. This turns the tube into a weak negative prism, with the environmental air as the "denser" material. Removing the air simply misaligned the cavity. The solution was to make one window "face up" and the other "face down" so they were exactly parallel. We note that all commercial ion lasers have both windows "face up" for easy cleaning, requiring realignment with changing altitude.

In the early all-fused-silica discharge tubes, the coolant in the water jacket is exposed to intense ultraviolet from the discharge. This was brought home to us painfully, when the plant engineering staff at HRL shut us down. It seems that this UV light polymerized the anti-algae agent they added to the cooling water to keep the cooling tower clean, and we had been creating "sludge" in their system for months. Needless to say, they were very unhappy with us when they finally discovered what was happening.

\section{OTHER EARly ION LASER APPLICATIONS}

In the period 1964 to 1970 , many applications using gaseous ion lasers were pursued by research and development groups worldwide. These included projection color TV, high-speed data recording on film, eye surgery (see the excellent review by E. I. Gordon elsewhere in this special issue), dye laser pumping, even disco light shows! Hughes being an aerospace firm, our customers were usually government agencies.

In these early years, HRL built several "one-off" CW argon ion lasers for various applications. We built a 1-W laser in 1965 for a prototype laser space communications system developed by the Hughes Aerospace Group for NASA Houston. This system used digital polarization modulation at $30 \mathrm{Mb} / \mathrm{s}$ to transmit one video channel. When demonstrated over the "four-mile range" at the Hughes Culver City facility, we had to add 30-dB optical attenuation to keep the detectors from saturating. We estimated this system would have provided a $30-\mathrm{Mb} / \mathrm{s}$ channel to the moon. We built a $\mathrm{CW}$ argon ion laser system for NASA Huntsville in 1966 for space illumination experiments from a small telescope dome there. The biggest problem with this particular system was building a coolant-to-air heat exchanger that would work 100 feet away from the laser and the dome, and would not freeze in the Huntsville winters.

About 1968, the Hughes systems people embarked on a different airborne application, a forward-looking imaging system that used a 2-W argon ion laser scanned in a TV-like raster, with a synchronously scanned receiving telescope. HRL was again enlisted to provide a qualified laser for this system. Our laser design was essentially the same as that for the AN/AVD-3 line scanner, but the package had to be different because the laser was now to be mounted on the outer skin of the aircraft! It seems that there was not enough room in the nose for the scanning optics and the laser too, so we were relegated to the slipstream. Fig. 7 is a picture of a Douglas A-26 of the "Hughes Air Force," with the system installed, and our laser mounted on the outside (arrow). The beak-like assembly is an optical window that allowed the system to be pointed at angles between straight ahead and straight down. One night this system was flown from the Hughes airstrip in Culver City, CA, to San Diego, to rendezvous with and image a submarine surfaced off shore. This was done, and then the pilot decided to fly back to Culver City with the system pointed straight down, using the TV display of the highway to chart his way back. A later version of this system was to add range-finding capability on any pixel of the raster by pulsing the laser to ultraviolet output for that pixel [63]. This latter system was not built, although the concept was demonstrated at HRL.

From time to time in 1965-1970, we would get requests for proposals for underwater applications. The argon ion blue-green lines are in the optical "window" for water centered around 470-500 $\mathrm{nm}$ (depending on where the water is located geographically). We would respond with designs ranging from simple modifications of our airborne systems to proposed development of 100-W and 1000-W output ion lasers. (Operation from an underwater platform seemed attractive since infinite cooling capacity was readily available, or so we imagined.) None of these ideas got beyond the proposal stage. Eventually cooler heads would prevail and realize that light attenuates very rapidly when it decays exponentially with distance, with $1 / e$ lengths of 5 to 20 meters, rather than as an inverse square law. 


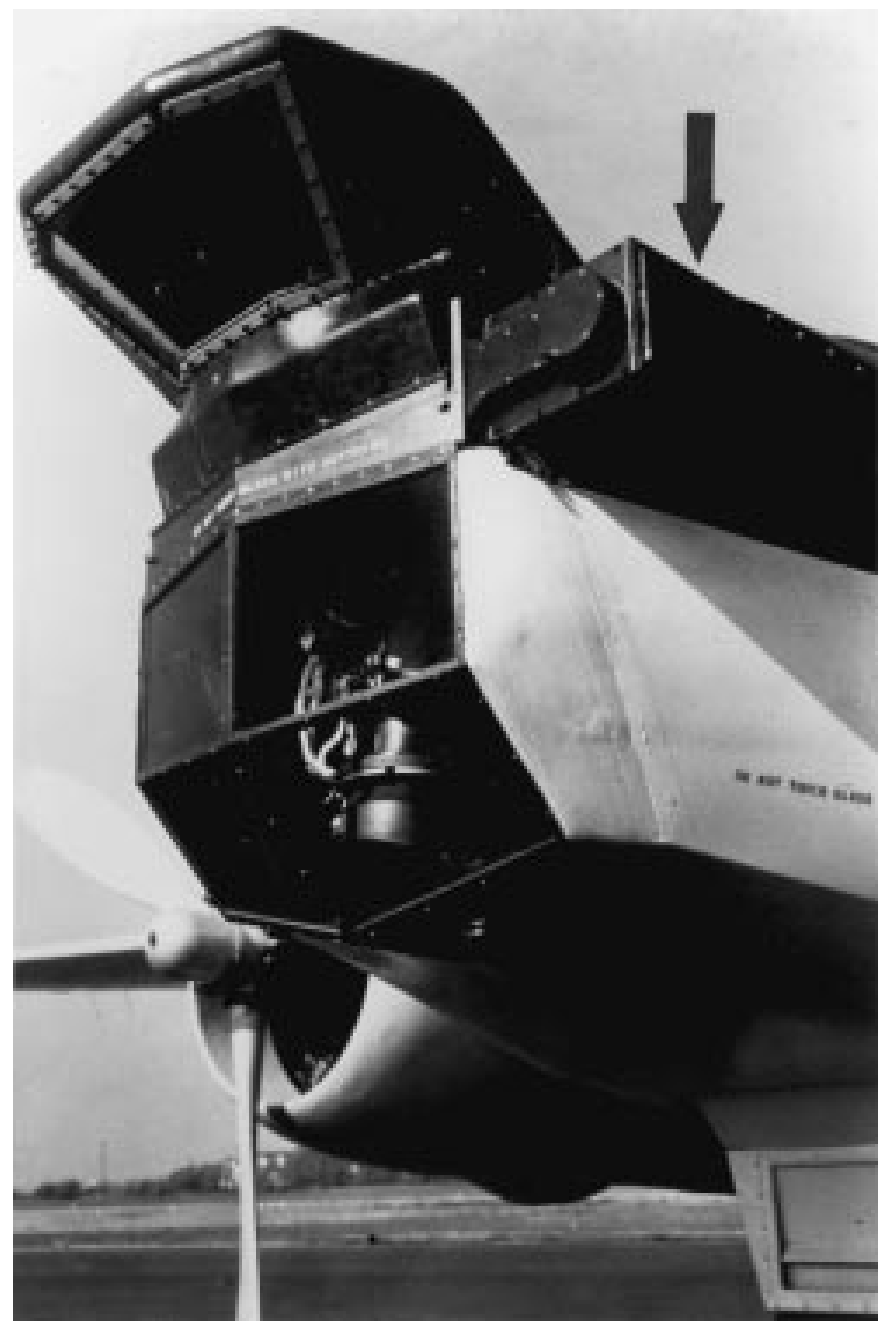

Fig. 7. Forward-looking laser imaging system which used a TV-like raster scan. The argon ion laser is mounted on the outside of the aircraft skin (arrow). This system was built by the Hughes Aircraft Company, Aerospace Division, CA, 1968.

One last laser "application" is worth special mention. In 1967, Prof. C. O. Alley of the University of Maryland considered directing a ruby laser at the Hughes/JPL/NASA Surveyor VII spacecraft, then sitting on the surface of the moon. That craft had successfully completed all its mission requirements and had (unexpectedly) survived the lunar night. It had a video camera aboard to view "digging in the lunar soil," but the camera could also be oriented to view the earth. And it was just sitting there, with nothing to do. Michael Shumate of Caltech's JPL suggested to Alley that he needed a CW ion laser rather than a pulsed ruby laser, since the chances of the Surveyor camera's video scan coinciding with the arrival of a pulse were next to zero. Alley called all around the country looking for a laser to borrow, but most groups (including us) had only laboratory lash-ups at that early date. He eventually found one to borrow at Spectra Physics, one of their $\mathrm{r}-\mathrm{f}$ excited units. However, all his telephone calls stimulated an interest in participating, even if it meant dealing with our laboratory "kluges." With Shumate as our team leader, we moved our laboratory 2-W tube up to Table Mountain near Wrightwood, CA, where JPL had a small observatory with a 24-inch telescope. This was all done "after hours"

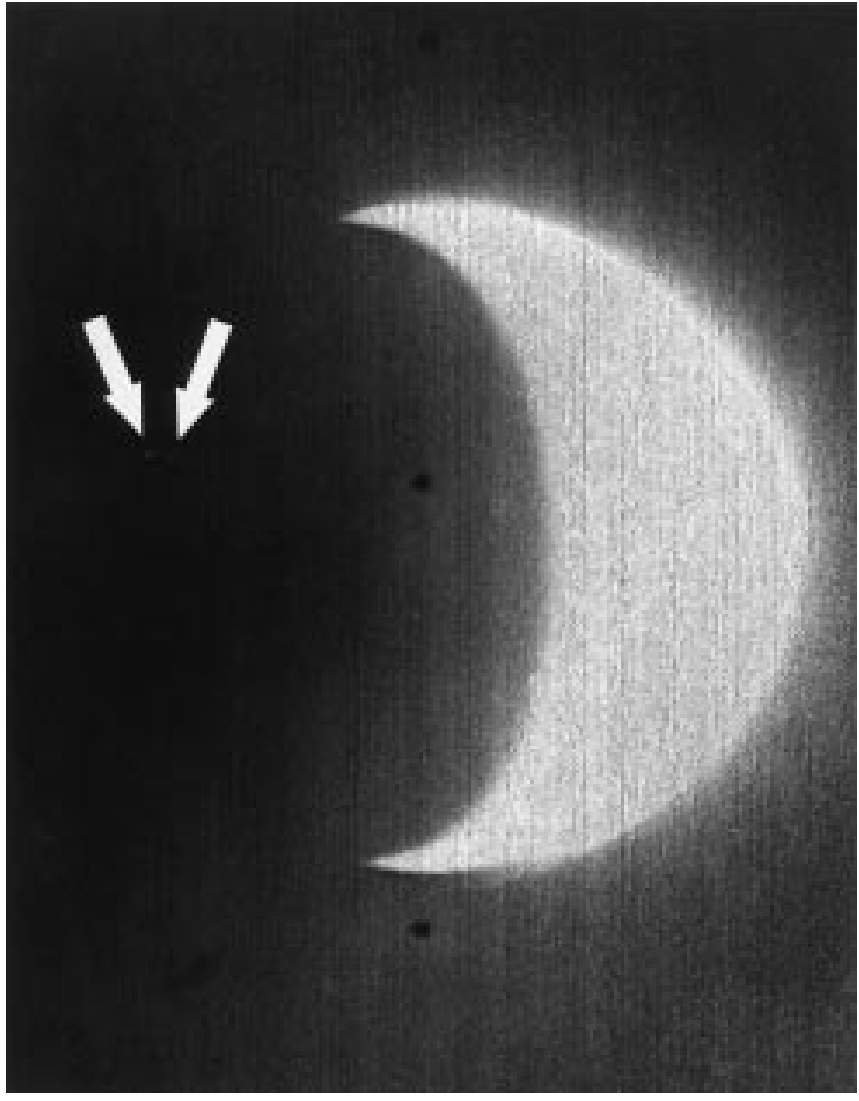

Fig. 8. Video frame of the earth, taken from the Surveyor VII spacecraft on the moon, January 20, 1968. Several lasers are pointed at the camera from the earth, but only the ones from Table Mountain (left arrow) and Kitt Peak (right arrow) can be detected.

at HRL, and at no cost, since this was not an official program of any sort for us.

We were not the only ones so moved to participate on their own! On the night of the test in January 1968, several groups were pointing telescopes and argon ion lasers at the moon (and, hopefully, at the location of the Surveyor spacecraft): Alley was at Kitt Peak National Observatory, using the McMath 60-inch Solar telescope and a borrowed 2-W Spectra Physics laser; a group at Raytheon Research Laboratories at Waltham, MA, had a laboratory laser with $60-\mathrm{W}$ output, with the beam directed out a window to a 4 -inch portable telescope in the parking lot (with ten undergraduate students from Wesleyan University to help); a group at NASA Goddard, Greenbelt, MD, using a 10-W RCA laser and an existing 5.5-inch satellite tracking telescope; a group at Perkin-Elmer, Norwalk, CT, using a 2-W laser built by Perkin-Elmer and Mr. R. Perkin's personal 24-inch telescope; a group at MIT Lincoln Laboratories, using a loaned 3.5-W Spacerays laser, and an 3-inch telescope with az-el gimbels; and our gang at Table Mountain, CA, with a 2-W HRL-built laser and the 24-inch telescope. Fig. 8 shows the result. The two white spots indicated by the arrows are Table Mountain on the left and Kitt Peak on the right. The groups on the east coast of the U.S. are not seen (and further image processing by JPL failed to bring them out). By the time the experiment was executed, the pre-dawn sunlight provided an unfortunate background for the East Coast groups. Another contributing factor was the skill required in pointing the telescope to the proper spot on the moon. 
Both our group and Alley's had skilled astronomers directing the telescope through a dichroic mirror at lunar features known to be at the Surveyor location. After the experiment, the astronomer directing our telescope let me look at these "features," which appeared to me as only a vague blur. I do not know how he saw "craters." A brief summary of this experiment is given in [64].

\section{Philosophical ObSERVATION}

My intent in writing this paper was not to give a polished summary of the theory and practice of ion lasers, but rather to provide a historical account of "how it happened," at least from one person's viewpoint. Some record should exist of the fits and starts and dead-end ideas as well as the successes that lead to the present state of an art. It should give some comfort to the newcomer who may be intimidated by the very pat-sounding development of science and technology typically given in the classroom. Good people make mistakes, and learn from them. And there is a tremendous thrill when everything finally works!

\section{ACKNOWLEDGMENT}

The author would like to thank the people at HRL: A. N. Chester, P. O. Clark, V. Evtuhov, H. R. Friedrich, A. S. Halsted, R. B. Hodge, G. N. Mercer, J. K. Neeland, J. V. Parker, M. R. Smith, R. Smith, D. Sobieralski, the Department Manager D. C. Forster, and three different Laboratory Directors during 1964-1972: M. R. Currie, L. M. Field, and G. F. Smith. At Hughes Electron Dynamics Division: D. E. Crane, D. D. Hallock, W. P. Kolb, A. G. Peifer. At the Hughes Aerospace Group: J. C. Hill. At Bell Laboratories, E. I. Gordon, E. F. Labuda, R. C. Miller, W. T. Silfvast, C. E. Webb. At Spectra Physics: W. E. Bell, A. L. Bloom, J. P. Goldsborough, R. C. Rempel. At RCA: J. R. Fendley, Jr., K. G. Hernqvist. At the Lebedev Institute: N. N. Sobolev; At WPAFB: R. Firsdon, W. C. Schoonover. At JPL: M. S. Shumate.

\section{REFERENCES}

[1] W. E. Bell, "Visible laser transitions in $\mathrm{Hg}^{+}$," Appl. Phys. Lett., vol. 4, pp. 34-35, Jan. 15, 1964.

[2] W. B. Bridges, "High optical gain at 3.5- $\mu \mathrm{m}$ in pure xenon," Appl. Phys. Lett., vol. 3, pp. 45-47, Aug. 1, 1963.

[3] — , "Atomic and ionic gas lasers," in Methods of Experimental Physics, Volume 15: Quantum Electronics, Part A. ser. L. Marton, C. L. Tang, Ed. New York: Academic, 1979, pp. 31-166.

[4] W. E. Bell. Communicated to me in July 2000 by R. L. Byer, Stanford University, who as a student had worked with Bell at Spectra Physics, , 1964.

[5] G. Convert, M. Armand, and P. Martinot-Lagarde, "Effet laser dans des mélanges mercure-gaz rares," Compt. Rend. Acad. Sci. Paris, vol. 258, pp. 3259-3260, Mar. 23, 1964.

[6] G. R. Harrison, M. I. T. Wavelength Tables. New York: Wiley, 1952.

[7] L. Minnhagen, "The spectrum of singly ionized argon," Ark. Fys., vol. 25, pp. 203-284, 1963.

[8] W. B. Bridges, "Laser oscillation in singly ionized argon in the visible spectrum," Appl. Phys. Lett., pp. 128-130, Apr. 1, 1964.

[9] G. Convert, M. Armand, and P. Martinot-Lagarde, "Transitions laser visibles dans l'Argon ionisé," Compt. Rend. Acad. Sci. Paris, vol. 258, pp. 4467-4469, May 4, 1964.

[10] W. R. Bennett Jr., J. W. Knutson Jr., G. N. Mercer, and J. L. Detch "Super-radiance, excitation mechanisms and quasi-CW oscillation in the visible $\mathrm{Ar}^{+}$laser," Appl. Phys. Lett., vol. 4, pp. 180-182, May 15, 1964.
[11] W. B. Bridges, "Ionized noble gas laser," U. S. Patent 3395 364. Assigned to Hughes Aircraft Company, July 30, 1968.

[12] - "Laser action in singly ionized krypton and xenon," Proc. IEEE, vol. 52, pp. 843-844, July 1964.

[13] W. B. Bridges and A. N. Chester, "Visible and UV laser oscillation at 118 wavelengths in ionized neon, argon, krypton, xenon, oxygen, and other gases," Appl. Opt., vol. 4, pp. 573-580, May 1965.

[14] Handbook of Chemistry and Physics, 32nd ed., C. D. Hodgman, Ed., Chemical Rubber Co., Cleveland, OH, 1950, pp. 2304-2319.

[15] C. E. Moore, Atomic Energy Levels, ser. National Bureau of Standards Circular 467: U. S. Government Printing Office, 1949, 1952, 1958, vol. I-III.

[16] C. J. Humphreys, "Second spectrum of xenon," J. Res. Natl. Bur. Stand. (U.S.), vol. 22, pp. 19-53, Jan. 1939.

[17] — , "Third spectrum of xenon," J. Res. Natl. Bur. Stand. (U.S.), vol. 16, pp. 639-648, June 1936.

[18] C. J. Humphreys, W. F. Meggers, and T. L. deBruin, "Zeeman effect in the second and third spectra of xenon," J. Res. Natl. Bur. Stand. (U.S.), vol. 23, pp. 683-699, Dec. 1939.

[19] Anonymous, "LGI.37 high power pulsed optical quantum generator," in The 1970 World's Fair, Osaka, Japan, specification sheet handed out at the Soviet Union laser exhibit.

[20] J. B. Marling, "Ultraviolet ion laser performance and spectroscopy-I. New strong noble-gas transitions below 2500 A," IEEE J. Quantum Electron., vol. QE-11, pp. 822-834, Oct. 1975.

[21] W. B. Bridges and A. N. Chester, "Spectroscopy of ion lasers," IEEE J. Quantum Electron., vol. QE-1, pp. 66-84, May 1965.

[22] _ , "Ion lasers," in Handbook of Lasers With Selected Data on Optical Technology, R. J. Pressley, Ed. Cleveland, OH: CRC Press, 1971, pp. 242-297.

[23] W. B. Bridges, "Ionized gas lasers," in Handbook of Laser Science and Technology, Vol. II-Gas Lasers, M. J. Weber, Ed. Boca Raton, FL: CRC Press, 1982, pp. 171-269.

[24] M. J. Weber, Handbook of Laser Wavelengths. Boca Raton, FL: CRC Press, 2000.

[25] G. R. Fowles and W. T. Silfvast, "Laser action in the ionic spectra of Zinc and Cadmium," IEEE J. Quantum Electron., vol. QE-1, p. 131, June 1965 .

[26] W. T. Silfvast, "Efficient CW laser oscillation at 4416 A in Cd(II)," Appl. Phys. Lett., vol. 13, pp. 169-171, Sept. 1, 1968.

[27] H. G. Cooper and P. K. Cheo, "Ion laser oscillations in sulfer," in Proc. Physics of Quantum Electronics Conf. San Juan, Puerto Rico, 1965, pp. 690-697.

[28] P. K. Cheo and H. G. Cooper, "UV and visible laser oscillations in fluorine, phosphorus, and chlorine," Appl. Phys. Lett., vol. 7, pp. 202-204, Oct. 1, 1965.

[29] K. Jain, "A nickel ion laser," Appl. Phys. Lett., vol. 34, pp. 845-846, June $15,1979$.

[30] J. R. McNeil, G. J. Collins, K. B. Persson, and D. L. Franzen, "CW laser oscillation in Cu II," Appl. Phys. Lett., vol. 27, pp. 595-598, Dec. 1, 1975.

[31] J. R. McNeil, W. L. Johnson, G. J. Collins, and K. B. Persson, "Ultraviolet laser action in He-Ag and Ne-Ag mixtures," Appl. Phys. Lett., vol. 29, pp. 172-174, Aug. 1, 1976.

[32] R. D. Reid, J. R. McNeil, and G. J. Collins, "New ion laser transitions in He-Au mixtures," Appl. Phys. Lett., vol. 29, pp. 666-668, Nov. 15, 1976.

[33] E. I. Gordon, E. F. Labuda, and W. B. Bridges, "Continuous visible laser action in singly ionized argon, krypton, and xenon," Appl. Phys. Lett., vol. 4, pp. 178-180, May 15, 1964.

[34] M. H. Dunn and J. N. Ross, "The argon ion laser," in Progress in Quantum Electronics, J. H. Sanders and S. Stenholm, Eds. New York: Pergamon, 1976, vol. 4, pp. 233-269.

[35] C. C. Davis and T. A. King, "Gaseous ion lasers," in Advances in Quantum Electronics, D. W. Goodwin, Ed. New York: Academic, 1975, vol. 3, pp. 169-469.

[36] E. F. Labuda, E. I. Gordon, and R. C. Miller, "Continuous-duty argon ion lasers," IEEE J. Quantum Electron., vol. QE-1, pp. 273-279, Sept. 1965.

[37] I. P. Zapesochnyi, A. I. Imre, A. I. Daschenko, V. S. Vukstich, F. F. Danch, and V. A. Kel'man, "Experimental investigation of the excitation of Ar II and Kr II in electron-ion collisions" (in English), Sov. Phys._JETP, vol. 36, pp. 1056-1060, June 1973.

[38] E. F. Labuda, C. E. Webb, R. C. Miller, and E. I. Gordon, "A study of capillary discharges in noble gases at high current densities," in 18th Gaseous Electronics Conference, Minneapolis, MN, 1965. 
[39] R. I. Rudko and C. L. Tang, "Excitation mechanisms in the Ar II laser," Appl. Phys. Lett., vol. 9, pp. 41-44, July 1, 1966.

[40] W. B. Bridges and A. S. Halsted, "Gaseous ion laser research," Hughes Research Laboratories, Malibu, CA, Final Tech. Rep. AFAL-TR-67-89, NTIS Accession Number AD814 897, May 1967.

[41] V. F. Kitaeva, A. N. Odintsov, and N. N. Sobolev, "Continuously operating argon ion lasers" (in English), Sov. Phys.-Usp., vol. 12, pp. 699-730, May-June 1970.

[42] W. B. Bridges, A. N. Chester, A. S. Halsted, and J. V. Parker, "Ion laser plasmas," Proc. IEEE, vol. 59, pp. 724-737, May 1971.

[43] E. I. Gordon and E. F. Labuda, "Gas pumping in continuously operated ion lasers," Bell Syst. Tech. J., vol. 43, pp. 1827-1829, July 1964.

[44] W. B. Bridges and G. N. Mercer, "Ultraviolet ion lasers," Hughes Research Laboratories, Tech. Rep. ECOM-0229-F, NTIS Accession Number AD861 927, Oct. 1969.

[45] A. N. Chester, "Experimental measurements of gas pumping in an argon discharge," Phys. Rev., vol. 169, pp. 184-193, May 5, 1968.

[46] W. F. Matthews and R. F. Jung, "Laser line-scanning sensors," Opt. Eng., vol. 14, pp. 116-119, Mar./Apr. 1975.

[47] D. C. Forster, "High power millimeter wave sources," in Advances in Microwaves. New York: Academic, 1968, vol. 3, pp. 301-346.

[48] J. R. Fendley and K. G. Hernqvist, "Construction of long-life argon lasers," in Int. Electron Devices Meeting, Washington, D.C., Oct. 26, 1966.

[49] A. S. Halsted, W. B. Bridges, and G. N. Mercer, "Gaseous ion laser research," Hughes Research Laboratories, Final Tech. Rep. AFAL-TR-68-227, NTIS Accession Number AD 841834, July 1968.

[50] D. A. Huchital and J. D. Rigden, "Argon laser action in a thermionic hollow cathode discharge," IEEE J. Quantum Electron., vol. QE-3, pp. 378-379, Sept. 1967

[51] T. F. Johnston and A. S. Halsted, "Manufacturing methods program-5 W CW argon ion laser, Vol.I: Argon Ion Laser Manufacturing; Vol.II: Installation and Operating Instructions; Vol.III: Production Documentation," Hughes Aircraft Electron Dynamics Division, Tech. Rep. AFML-TR-73-108, June 1973.

[52] J. R. Fendley and J. J. O'Grady, "Development, construction, and demonstration of a 100-W CW argon ion laser," RCA, Tech. Rep. ECOM-0246-F, Dec. 1970

[53] G. N. Alferov, V. I. Donin, and B. Y. Yurshin, "CW argon laser with 0.5-kW output power" (in English), JETP Lett., vol. 18, pp. 369-370, Nov. 20, 1973

[54] W. E. Bell, "Ring discharge excitation of gas ion lasers," Appl. Phys. Lett., vol. 7, pp. 190-191, Oct. 1, 1965.

[55] J. P. Goldsborough, E. B. Hodges, and W. E. Bell, "RF induction excitation of CW visible laser transitions in ionized gases," Appl. Phys. Lett., vol. 8, pp. 137-139, Mar. 15, 1966.

[56] J. P. Goldsborough, Spectra Physics, private communication, 1967.

[57] I. Kato and T. Shimizu, "Microwave pulse excited argon ion laser," Electron. Commun. Jpn., vol. 55-C, no. 7, pp. 108-114, 1972.

[58] J. P. Goldsborough, "Cyclotron resonance excitation of gas-ion laser transitions," Appl. Phys. Lett., vol. 8, pp. 218-219, May 1, 1966.

[59] S. G. Kulagin, V. M. Likhachev, E. V. Markuzon, M. S. Rabinovich, and V. M. Sutovskii, "States with population inversion in a self-compressed discharge" (in English), JETP Lett., vol. 3, pp. 6-8, Jan. 1, 1966.

[60] R. Illingworth, "Laser action and plasma properties of an argon Z-pinch discharge," J. Phys. D—Appl. Phys., vol. 3, pp. 924-930, 1970.

[61] A. Papayoanou and I. M. Gunmeiner, "High power xenon laser action in high current pinched discharges," Appl. Phys. Lett., vol. 16, pp. 5-8, Jan. 1, 1970.

[62] P. Mace, Los Alamos National Laboratories, private communication, 1965.
[63] W. B. Bridges, W. O. Edlun, and J. C. Hill, "Scanned laser imaging and ranging system," U. S. Patent 3897 150. Assigned to the Hughes Aircraft Company, July 29, 1975.

[64] C. O. Alley and D. G. Currie, "XI. Laser beam pointing tests," in Surveyor II Mission Report, Part II. Science Results. Pasadena, CA: Jet Propulsion Laboratory, Mar. 15, 1968.

[65] W. B. Bridges, "Laser oscillation in singly ionized argon in the visible spectrum," Erratum, Appl. Phys. Lett., p. 39, July 15, 1964.

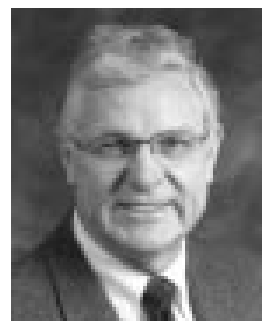

William B. Bridges (S'53-M'61-F'70-LF'97) was born in Inglewood, CA, in 1934. He received the B.S., M.S., and Ph.D. degrees in electrical engineering from the University of California, Berkeley, in 1956, 1957, and 1962, respectively. His graduate research dealt with noise in microwave tubes and electron-stream instabilities (which later became the basis of the Vircator.)

$\mathrm{He}$ was an Associate in electrical engineering at the University of California, Berkeley, from 1957 to 1959 , teaching courses in communication and circuits. Summer jobs at RCA and Varian provided stimulating experience with microwave radar systems, ammonia beam masers, and the early development of the ion vacuum pump. He joined the Hughes Research Laboratories, Malibu, CA, in 1960 as a Member of the Technical Staff and was a Senior Scientist from 1968 to 1977, with a brief tour as Manager of the Laser Department in 1969-1970. His research at Hughes involved gas lasers of all types and their application to optical communication, radar, and imaging systems. He is the discoverer of laser oscillation in noble-gas ions and spent several years on the engineering development of practical high-power visible-light and ultraviolet ion lasers for military applications. He joined the faculty of the California Institute of Technology in 1977 as Professor of Electrical Engineering and Applied Physics, serving as Executive Officer for Electrical Engineering from 1979 to 1981. In 1983, he was appointed Carl F. Braun Professor of Engineering and conducted research in optical and millimeter-wave devices and their applications. He was a Sherman Fairchild Distinguished Scholar at Caltech in 1974-75, and a Visiting Professor at Chalmers Technical University, Göteborg, Sweden, in 1989. He is co-author (with C. K. Birdsall) of Electron Dynamics of Diode Regions (New York: Academic, 1966.) He has served on various committees of both IEEE and OSA, and was formerly Associate Editor of the IEEE JOURNAL OF QUANTUM ELECTRONICS and the Journal of the Optical Society of America. He was the President of the Optical Society of America in 1988, a member of the U.S. Air Force Scientific Advisory Board 1985 - 89, and a member of the Board of Directors of Uniphase Corporation 1986-98. His current research includes the millimeter-wave modulation of light and high-fidelity analog microwave photonic links.

Dr. Bridges is a member of Eta Kappa Nu, Tau Beta Pi, Phi Beta Kappa, and Sigma Xi, receiving Honorable Mention from Eta Kappa Nu as an "Outstanding Young Electrical Engineer" in 1966. He was awarded the Arthur L. Schawlow Medal from the Laser Institute of America in 1986 and the IEEE LEOS Quantum Electronics Award in 1988, and was recognized as a Distinguished Engineering Alumnus by the University of California, Berkeley, in 1995. He received the Distinguished Teaching Award in 1980 and 1982 and the Lifetime Excellence in Teaching Award in 2000 from the Associated Students of Caltech. He is a member of the National Academy of Engineering and the National Academy of Sciences, and a Fellow of the Optical Society of America and the Laser Institute of America. 